\title{
Primary Peritoneal Carcinosarcoma
}

National Cancer Institute

\section{Source}

National Cancer Institute. Primary Peritoneal Carcinosarcoma. NCI Thesaurus. Code C159507.

An extremely rare and highly aggressive malignant neoplasm arising from the peritoneum. Morphologically, it is a high grade tumor, composed of carcinomatous and sarcomatous elements. 